\title{
LO QUE TODAVÍA NO SABES ACERCA DE LA ÚLTIMA NOVELA DE EFRAIM MEDINA REYES
}

Jimmy Humberto Fortuna Vargas*

jifort@yahoo.com
"Ser veloz o lento me da igual, mi ritmo ideal es el que me procuran los detalles, por eso mis historias no son uniformes, saltan, se atascan y tienen rayas"

Efraim Medina

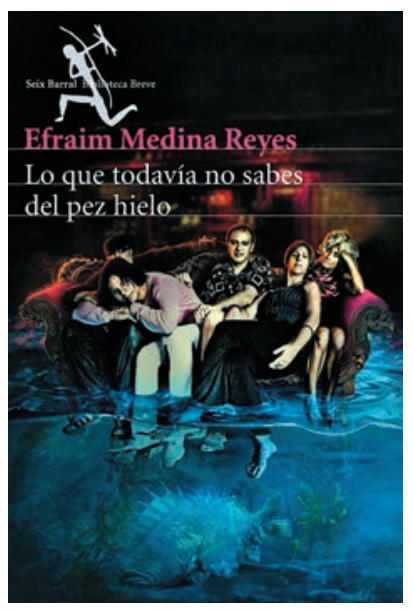

Imagen http://4.bp.blogspot.com/nfILeaQ2Chc/UO2iFm6-pZI/AAAAAAAACaY/WeMAzYaXUnU/s1600/430168 _459875047389168_340814338_n.jpg

"Lo que todavía no sabes del pez hielo" es la última obra publicada por el escritor cartagenero Efraim Medina Reyes en la que, como alguna vez me dijo en una versión del Hay Festival, se alejaría de lo que abordó en su famosa trilogía: "Érase una vez el amor pero tuve que matarlo", "Técnicas de masturbación entre Batman y Robin" y "Sexualidad de la Pantera Rosa", novelas que lo catapultaron al mundo de las editoriales, $y$, especialmente, al de los ávidos lectores de novelas que estaban deseosos de salir del lugar común y de asumir la crudeza que tiene la vida, ambientada con un poco de rock y blues y estrambóticos personajes tan cercanos a todos nosotros.

Toda novela tiene su destinatario ideal y en el caso de la obra Medina Reyes, este debe asumir el reto de leer 489 páginas que conforman el mundo literario que subyace en este libro en el que la comicidad se asume como uno de los hilos más fuertes de este tejido en el que los personajes deambulan por esa ya conocida ciudad que los reúne: Ciudad Inmóvil. A diferencia de las anteriores novelas del autor de "Cinema árbol", esta ofrece, a través de su narrador protagonista, un sinfín de reflexiones en torno a las forma de vida de quienes asumieron como patria chica su sufrida y vapuleada ciudad. Prueba de ello son los siguientes apartes: “La gente de Ciudad Inmóvil no tiene un concepto del individuo, vive en una inminente interacción con los demás [...]. Contarle su vida a un desconocido no le toma más de tres o cuatro minutos a un habitante de Ciudad Inmóvil [...] Bailar es la religión de Ciudad Inmóvil. Quien no baila no tiene amigos, no tiene novia, no tiene puta, no tiene contactos, no tiene ninguna posibilidad [...]. El baile es el centro de las emociones y el único diálogo seguro [...]. El baile es improvisación al estado puro, riesgo de muerte, vértigo". En la mitad del libro, surge otra mención. En este caso es sobre los conductores de buses públicos: "El chofer es un dictador que impone el estilo y el volumen de la música, también el lugar donde el pasajero debe bajarse y que jamás corresponde a un paradero. Si le da la gana de detenerse ante la casa de una amante y hacer visita, lo hace". Hacia la parte final de la obra hay otra sobre la relación que entablan con el mar: "El mar es la única opción que ofrece Ciudad Inmóvil a la mayoría de sus habitantes, una opción que las playas privadas abusivas protegidas por guardias armados han ido reduciendo".

Como es común en las historias de este autor, amante del cine y de los cómics (Hulk, Turok, Batman, EI Llanero Solitario), estas no manejan una linealidad. Es factible pasar de una situación a otra entre una página y la siguiente. La novela está dividida en siete partes y crean la atmósfera de una obra sencilla, pero con el pasar de las líneas, va tomando la forma de una novela negra con un humor de la misma tonalidad. El protagonista, amante de la "comicidad conceptual" y presente en los siete momentos, es un joven de 27 años que, habitualmente, consume cocaína y siente debilidad por las mujeres, pese a demostrar una supuesta timidez. Su vida es plana, pero al inmiscuirse en el mundo del "Pez Hielo", su vida se 
trastorna, ya que conoce a un "trío poco común": "Una abogada que chupa drogas sintéticas como si fueran mentas, un italiano que se recupera de una sobredosis con tres gramos de cocaína colgados en el cuello y un chino que esperar usurpar el nombre de un muerto". Todos ellos conformarán su nueva familia, su nueva realidad.

Esta nueva obra de Medina Reyes, además del tema de la comicidad, ya mencionado, toma la familia como uno de sus ejes centrales. El personaje convive con su progenitora y hermanos, con quienes padece la rudeza de la vida, más inclemente que el clima de la ciudad en la que se enmarcan las múltiples historias de esta novela: "Marlon, el antiséptico y maniático del orden dueño del baño. El enemigo mortal del polvo, las manchas y los libros dejados por ahí. Mi insufrible hermano mayor". Acerca de su novia, Vlues, manifiesta: "Vlues porque ella es un blues [...]. Sin ella sería un pendejo, un énfasis sin criterio, un chico de mi edad sin atenuantes". En torno a los otros nombres de los miembros de la familia: "El nombre de Ariel proviene de una colección de libros y a mí me tocó en suerte llevar el de mi padre".

Teo, alter ego del protagonista, sucumbe a planteamientos cómicos, filosóficos y literarios (hay continuas menciones a Franz Kafka, Gloss Spencer, Lenny Bruce, Andy Kaufman, Arthur Shopenhauer, Teo Goldman, Gilles Deleuze y Cesare Pavese), los cuales alimentan sus textos para un posible espectáculo en el que la comedia sea la voz cantante: "Al individuo corriente lo abate el temor de perderse en el montón y por esto recurre a la impostura. No es que denigre de aquello que es sino que aquello que es prácticamente no existe", "Que no es la distancia sino la proximidad lo que nos hace invisibles", "Uno debería ser lo que sueña y no lo que hace", "El amor dura un instante, pero su sombra se alarga a través de los años y nos confunde", "Olvidar a alguien significa recordarlo", "La estupidez contemporánea deriva de los medios de comunicación", "Un libro puede ser el ataúd de quien lo escribe", "Lo cómico de los sentimientos es que son el pasado de una sensación: amamos a alguien porque lo hemos amado en algún momento", "Si mentir es un arte, pronto voy a ser una celebridad", "La mentira es el elemento clave de cualquier relación humana, es lo que desatasca las cañerías del amor y humaniza la convivencia”, "Lo más implacable es aquello que no existe", "El amor es estúpido y si no lo es, no es amor. Y si no duele no es amor. Y si no dura o no para siempre no es amor. Es por eso que es estúpido", "Pensar en lo que nos falta banaliza y hace falso lo que tenemos", "El presente siempre es un espasmo, una crisis que deja aversión", entre otros efectos.

El nombre de la novela, aunque ambiguo, tiene que ver con un bar que se llamaba "Pez Hielo" $y$, en otras ocasiones, el título de la obra se relaciona con sensaciones y percepciones frente a diferentes situaciones mundanas: "El pez hielo no tiene pensamientos ni deseos, no conoce a ningún otro pez de su especie, no quiere ir a otra parte porque no sabe que existe esa posibilidad". Por otro lado, el referente de los peces apunta a las dos mascotas de la familia del protagonista: Flora y Limón. Finalmente, en la novela se menciona un libro titulado "Lo que todavía no sabes del pez hielo". El nombre de este bar se convierte en un punto de encuentro para las insólitas situaciones por las que tendrá que atravesar el protagonista. Además, él recurre a este sitio, debido a que su mentor, Lenny Bruce, "sostenía que los bares eran la mejor escuela para un cómico, que en ninguna otra parte la gente normal podía sentirse más a gusto y apropiada". En dicho lugar, conoce a Lena, mujer que lo llevará a un desenfrenado mundo, muy al estilo de los que creó Andrés Caicedo en su célebre novela. Al igual que el texto de Caicedo, el de Medina Reyes se enriquece con menciones a diferentes artistas de la música: Michael Jackson, Celio González, Benny Moré y Joe Arroyo, entre otros.

Por momentos, al leer esta novela, se vive la sensación de estar releyendo parte del cuento que está en el libro de relatos "Cinema árbol": "La vieja radio Philips" donde se establece la relación entre los padres del protagonista y Lucho Gatica. Además, el personaje tiene que padecer las largas 
y eternas ausencias de su padre. El protagonista, en vista de los diferentes sucesos que experimenta, expresa: "Soy un decepcionador de oficio y trabajo a cualquier hora" $y$ "Siendo un adulto hecho y derecho he optado por hacer de la comicidad mi amigo imaginario, mi respuesta al aislamiento y la desazón que sigue emanando la realidad".
El reto que propone esta obra, además del gran número de páginas que la conforman, es el de tejer las múltiples historias que subyacen de este libro, el cual, permite ser leído de una manera amena, ya que la prosa de Efraím Medina Reyes es grata a los sentidos y los mundos de los personajes van hundiéndose en nuestra mente como una aguja en nuestra piel.

\section{Cómo citar (Reseña)}

Reyes Medina, E. (2012)Lo que todavía no sabes del pez hielo. Bogotá: Planeta (Seix Barral) 